\title{
The Design of the Performance Test Laboratory of Open Refrigerated Display Cabinets Based on Enthalpy Potential Method
}

\author{
Shuai $\mathrm{Li}^{\mathrm{a}}$, Lei Li ${ }^{\mathrm{b}}$ \\ Department of Mechanical and Electrical Engineering, Zaozhuang University, Zaozhuang 277160, \\ China \\ alishuai66@163.com, ba7082928@126.com
}

Keywords: refrigerated display cabinets, enthalpy potential method, performance test.

\begin{abstract}
According to the national standard Minimum allowable values of energy efficiency and energy efficiency grades of commercial refrigerating appliances-Part 1: Refrigerated display cabinets with remote condensing unit and GB/T21001-2007 Refrigerated Display Cabinets, this paper illustrates the design of the performance test laboratory of open refrigerated display cabinets based on enthalpy potential method. In the lab, the experiments of limiting operating conditions and speed adjustment of it in the inner space are undertaken.
\end{abstract}

\section{Introduction}

With the development of economy in China, a high requirement is proposed in sanitation, security and refreshment of food. All kinds of refrigerated display cabinets are widely used in the market, and the most common ones are open type and enclosed type. The key reason of the high energy consumption is the serious leak of cooling air. Axwell ${ }^{[1]}$, Xueqin ${ }^{[2]}$ and other experts find that the leak takes up of $60 \%-70 \%$ of the total load. Compared to the enclose one, except for the extra $50 \%$ of the electricity consumption of the open cabinet, the open one is popular among customers for its huge capacity and convenience. Therefore, scholars at home and abroad are positively research and develop the open type. For example, the efficiency of gas curtain type can be enhanced the by $5 \%-10 \%{ }^{[3]}$.

\section{Lab with enthalpy potential method}

Lab with enthalpy potential method is an important place to test the performance of refrigeration products. This method has become the main way of developing new products and testing the finished products to the refrigeration equipment manufacturers, and also the main tool of evaluating the quality of products to Quality supervision and inspection agencies at all levels. There is a rule about the performance of refrigerated display cabinets in the classification, requirement and test in part two of GB/T21001-2007 Refrigerated Display Cabinets. M-package, whose main ingredients are water and hydroxyethyl methyl cellulose, is required in the experiment. The detailed requirements are listed in table 1.

Test equipment's of air enthalpy method mainly include adiabatic warehouse (including indoor and outdoor sides), air reprocessing system, air sampling device, air receiving and mixing device, blast capacity measurement devices, and etc. Because of the intellectual property and other issues related to economic interests, domestic information published at home and abroad is very little. The United States HVAC Association standards ANSI / ASHRAE 116-1983 ${ }^{[4]}$, Japan Refrigeration and Air Conditioning Industry Association TP02-96 ${ }^{[5]}$ and refrigerated display cabinets standard GB / $\mathrm{T} 21001-2007^{[6]}$ in our country all list the regulations about totality, principles and accuracy of the test equipments with air enthalpy method.

A lot of explorations are done by some domestic researchers to improve the accuracy of the enthalpy potential method test. Zhong Xiaohui and other experts in Beijing University of Technology propose the methods to measure air flow and average temperature of cross section by measuring the air volume and velocity to weighting the temperature. In this way, limitation of temperature 
measurement stationing can be reduced and measurement accuracy can be improved ${ }^{[7]}$. Zhang Xiaosong and other experts in Southeast University propose to test the heating capacity with heat pump on the basis of the enthalpy potential method, which is called the ratio method ${ }^{[8]}$.

Table 1 Temperature Classification of M-package(unit:Celsius)

\begin{tabular}{cccc}
\hline type & $\begin{array}{l}\text { The highest temperature } \\
\text { of the hottest M package } \\
\leq\end{array}$ & $\begin{array}{c}\text { The lowest temperature of } \\
\text { the coldest M package } \geq\end{array}$ & $\begin{array}{c}\text { The lowest temperature of } \\
\text { the hottest M package } \leq\end{array}$ \\
\hline L1 & -15 & - & -18 \\
L2 & -12 & - & -18 \\
L3 & -12 & - & -15 \\
M1 & +5 & -1 & - \\
M2 & +7 & -1 & - \\
H1 & +10 & +1 & - \\
H2 & +10 & -1 & \\
S & & special types & \\
\hline
\end{tabular}

\section{Preparation of experimental environment}

The choice of air distribution form. Under normal circumstances, there is a certain degree of the indoor air flow and its flow direction nearly parallel with the opening side of the refrigerated display cabinet. So the air supply mode is from up to down to return air with full pore plate indoors and from down to up to return air outdoors. This reasonable way of air flow can give full play to the role of ventilation, eliminate the extra wet and heat in the lab, effectively discharge of harmful gases and suspended particles indoors, and also can make the indoor temperature and humidity distribution evenly with a small fluctuation range, which create favorable conditions for improving the accuracy of the test system. Pore plate cites a comprehensive one, and the specific parameters are determined according to the relevant national standards and actual situation in the laboratory. The air flow mode in the indoor side of the room is shown in Figure 1.

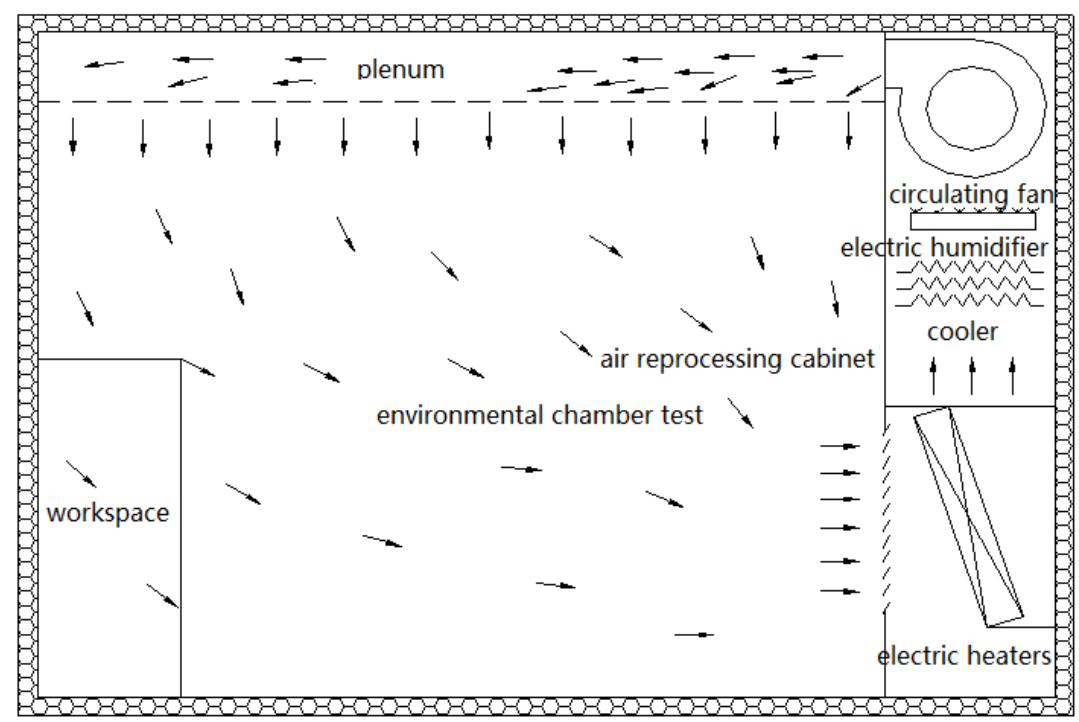

Fig .1 Schematic diagram of the air supply mode with pore plate

The choice and design of air heating mode. To make the laboratory environment under the setting conditions, the air around each side of the room is also needed to be heated. A large quality of power will be wasted in order to maintain the setting temperature when checking the showcase. So taking energy efficiency into consideration and also to enable laboratories to work in the winter, heated water / glycol system is used. The operating principle is showed in Figure 2. 


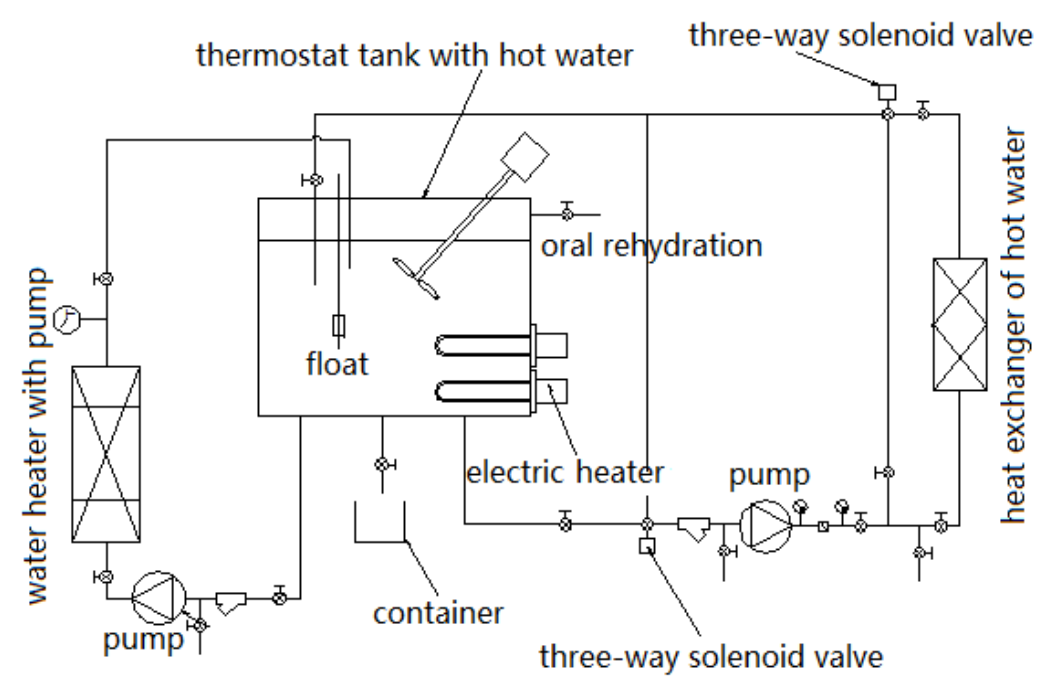

Fig .2 Schematic of heating system with heated hot water / glycol

\section{Calculation of cooling capacity}

Cooling consumption (Q) in the laboratory consists of four parts, namely: 1. calorific value of the equipment under test heat $\left(\mathrm{Q}_{1}\right)$, of which the maximum is selected; 2 . heat leaked through the warehouse plate $\left(Q_{2}\right)$ (the warehouse is built in the factory, so the radiant heat is neglected.); 3 . heat generated by various heating equipment in the room under operation, referred to as operating heat (Q3); 4. cooling capacity required to cool the room (Q4).

So: $Q=Q_{1}+Q_{2}+Q_{3}+Q_{4}$

The heat permeated from the outside for the temperature difference is called permeating heat, which can be calculated with the following formula:

$\mathrm{Q} 2=\mathrm{KA}(\mathrm{th}-\mathrm{tm})$

$\mathrm{K}$ - heat transfer coefficient, and the unit is $\mathrm{W} /(\mathrm{m} 2 \cdot \mathrm{K})$;

th—Calculating temperature outdoors, $\mathrm{th}=35^{\circ} \mathrm{C}$;

tm—-the setting temperature indoors, the minimum of which, $-15^{\circ} \mathrm{C}$,is chosen;

A__ gross area of the envelop enclosure

The material of the envelop enclosure is rigid polyurethane foam and spraying plastic steels of $10 \mathrm{~mm}$ thick are used in the inner side. Thermal resistant can be negligible and the heat transfer coefficient $\mathrm{K}$ (the unit is $\mathrm{W} /(\mathrm{m} 2 \cdot \mathrm{K})$ ) can be calculated as follows:

$$
K=\frac{1}{\frac{1}{\alpha_{1}}+\frac{\delta}{\lambda}+\frac{1}{\alpha_{2}}}
$$

$\alpha 1-$ heat transfer coefficient of the outer panel, $\alpha 1=23.26 \mathrm{~W} /(\mathrm{m} 2 \cdot \mathrm{K})$;

$\alpha 2$ - heat transfer coefficient of the inner pane, $\alpha 2=17.45 \mathrm{~W} /(\mathrm{m} 2 \cdot \mathrm{K})$;

$\lambda$ — thermal conductivity of the thermal insulation material, $\lambda=0.028 \mathrm{~W} /(\mathrm{m} \cdot \mathrm{K})$ 。

So: $\mathrm{K}=0.22 \mathrm{~W} /(\mathrm{m} 2 \cdot \mathrm{K})$

\section{The result of the test and conclusion}

To test the overall performance of the laboratory, experiments of limiting operating conditions and of speed adjustment are undertaken. An experiment of extreme humidity conditions under extreme heat is conducted on a side of the room, with the indoor side of the high temperature being $45^{\circ} \mathrm{C}$ and the maximum saturation humidity being 90\%. The experimental results are shown in Figure 3. 


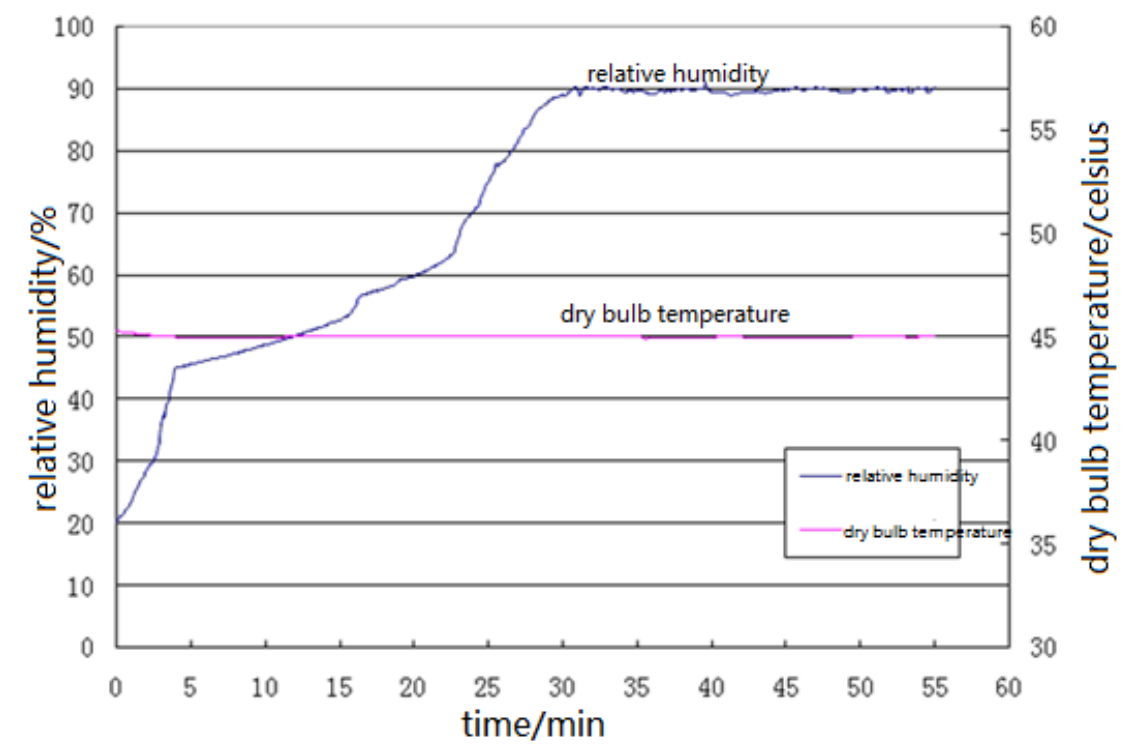

Fig .3 Experimental plot of extreme humidity conditions under extreme heat indoor

Experimental results show that to reach to 90 percent of the temperature designed costs less than an hour. Under the stabilized condition, the outputs of indoor chamber and the outer side are 39\% and 45\% respectively through the PID controller. During the experiment of operating conditions speed adjustment, the laboratory designed is able to meet the requirements either in extreme warming or cooling. The time of condition adjustment is less than 1.5 hours required by the technology and has a large margin. So the speed of condition adjustment can fully meet the technical requirements.

\section{References}

[1] Axell,M,Vertical Display Cabinets in Supermarket—Energy Efficiency and the Influence of Air Flows,Ph.D.thesis,Department of Building Services Engineering, Chalmers University of Technology, Sweden,2002.

[2] Xuequin,P.,Study and Modelling of a High Energy Efficiency Display Case,Center for Energy Studies.Ecole des Mines Paris,P.202,Paris,France,2000.

[3] Xie Wende,Xie Yanting,Lin Zhijie.The device of air-speed control on the open display cabinet. Refrigeration and air conditioning, December 2002, Article 18: 66-70.

[4] ASHRAE.Standard 79-78: Methods of Testing for Rating Room Fan-coil air conditiongers.

[5] TP02-96.The rules of Low temperature performance test in conservatory.

[6] GB/T21001-2007. Refrigerated display.

[7] Zhong Xiaohui,Wu Yuting,Zhang Xingzhou etc.Improvement of enthalpy measuring method for measuring heat capacity of heat pump.Journal of engineering thermophysics,Jul,2006,Suppl.2.

[8] Zhang Xiaosong,Wang Li,Ling Chen etc. Investigate of heat capacity measurement methods for air-side of the heat pump.Fluid machinery. 2000,Vol.28(10):55-58.

[9] Pren12900. Refrigerant compressors-Rating conditions.tolerances and presentation of manufacturer's performance data. 